\title{
Erratum to "Production of transgenic goat (Capra hircus) with human Granulocyte Colony Stimulating Factor (hG-CSF) gene in Brazil" [An Acad Bras Cienc 79(2007): 585-592]
}

\author{
VICENTE J.F. FREITAS ${ }^{1}$, IRINA A. SEROVA ${ }^{2,5}$, LYUDMILA E. ANDREEVA ${ }^{3}$, \\ GUENNADI A. DVORYANCHIKOV ${ }^{4}$, EDILSON S. LOPES-Jr. ${ }^{1}$, DÁRCIO I.A. TEIXEIRA ${ }^{1}$, \\ LUCIENE P.B. DIAS ${ }^{5}$, SUELY R.G. AVELAR ${ }^{1}$, RAYLENE R. MOURA ${ }^{1}$, LUCIANA M. MELO ${ }^{1}$, \\ ALEXSANDRA F. PEREIRA ${ }^{1}$, JOÃO B. CAJAZEIRAS ${ }^{1}$, MARIA L.L. ANDRADE ${ }^{1}$, \\ KARLLIELY C. ALMEIDA ${ }^{1}$, FRANCISCO C. SOUSA ${ }^{1}$, ANTONIO C.C. CARVALHO \\ and OLEG L. SEROV ${ }^{2}$ \\ ${ }^{1}$ Universidade Estadual do Ceará, Laboratório de Fisiologia e Controle da Reprodução \\ Av. Paranjana 1700, 60740-000 Fortaleza, CE, Brasil \\ ${ }^{2}$ Institute of Cytology and Genetics, Russian Academy of Sciences, Lavrentev av. 10, 630090 Novosibirsk, Russia \\ ${ }^{3}$ Institute of Molecular Genetics, Russian Academy of Sciences, Kurchatov sq. 2, 123182 Moscow, Russia \\ ${ }^{4}$ School of Medicine, University of Miami, Miami, Florida 33124, USA \\ ${ }^{5}$ Universidade Federal do Rio de Janeiro, Instituto de Biofísica Carlos Chagas Filho, CCS Bloco G, \\ Ilha do Fundão, 21949-900 Rio de Janeiro, RJ, Brasil
}

Manuscript received on December 1, 2006; accepted for publication on September 25, 2007; contributed by ANTONIO C.C. CARVALHO*

\section{CORRECTION}

— p. 585, Authors' names, line 5 Reads: “...Karlliely A. Castro ${ }^{1}, \ldots$. , Should read:

“...Karlliely C. Almeida ${ }^{1}, \ldots$,.

\footnotetext{
*Member Academia Brasileira de Ciências Correspondence to: Vicente José de F. Freitas E-mail: vjff@pq.cnpq.br
} 